\title{
Radiation Enhanced Anion Diffusion in Chromia
}

Kayla H. Yano ${ }^{* 1}$, Aaron A. Kohnert' ${ }^{2}$, Tiffany C. Kaspar ${ }^{3}$, Sandra D. Taylor ${ }^{3}$, Steven R. Spurgeon ${ }^{1}$, Hyosim $\mathrm{Kim}^{2}$, Yongqiang Wang ${ }^{2}$, Blas P. Uberuaga ${ }^{2}$, Daniel K. Schreiber ${ }^{1}$

${ }^{1}$ Energy \& Environment Directorate, Pacific Northwest National Laboratory, Richland, WA, 99354, USA

${ }^{2}$ Material Science and Technology Division, Los Alamos National Laboratory, Los Alamos, NM, 87545, USA

${ }^{3}$ Physical and Computational Sciences Directorate, Pacific Northwest National Laboratory, Richland, WA, 99354, USA

AUTHOR INFORMATION

Kayla H. Yano*

*Contact information: kayla.yano@pnnl.gov, (509)-375-2833

\section{Supplemental Material}

Irradiation

To determine irradiation conditions and calculate dose, Stopping Range of lons in Matter (SRIM) ${ }^{1}$ was used to simulate $400 \mathrm{keV} \mathrm{Ar}+$ irradiation on $\mathrm{Ni}(20 \mathrm{~nm}) / \mathrm{Cr}_{2}{ }^{\mathrm{NA}} \mathrm{O}_{3}(45 \mathrm{~nm}) / \mathrm{Cr}_{2}{ }^{18} \mathrm{O}_{3}(10 \mathrm{~nm}) / \mathrm{Cr}_{2}{ }^{\mathrm{NA}} \mathrm{O}_{3}$ (35 $\mathrm{nm}) / \mathrm{Al}_{2} \mathrm{O}_{3}(40 \mathrm{~nm})$. The "Quick KP" TRIM calculation method was used (Figure S1). Displacement energies for each species are as follows: $\mathrm{Ni}-40 \mathrm{eV}, \mathrm{Cr}-40 \mathrm{eV}, \mathrm{O}-28 \mathrm{eV}, \mathrm{Al}-25 \mathrm{eV} .^{2}$ At each layer interface, discontinuities in the SRIM calculated dose appear. Dose was measured at the $\mathrm{Cr}_{2}{ }^{18} \mathrm{O}_{3}$ layer, averaged over the $10 \mathrm{~nm}$ layer thickness. Final fluences were $3.88 \times 10^{15}$ ions $/ \mathrm{cm}^{2}$ for the $2 \mathrm{dpa}$ sample, $1.30 \times 10^{15}$ ions $/ \mathrm{cm}^{2}$ for the $0.66 \mathrm{dpa}$ sample, and $6.46 \times 10^{14}$ ions $/ \mathrm{cm}^{2}$ for the $0.33 \mathrm{dpa}$ sample (Table S1). The irradiation was conducted at the Los Alamos National Laboratory lon Beam Materials Laboratory. Schematic of the irradiation setup is shown in Figure S2. Samples were grown on $10 \times 10 \mathrm{~mm} \mathrm{Al}_{2} \mathrm{O}_{3}$ substrates, subsequently cleaved into $5 \times 5 \mathrm{~mm}$ sections and irradiated at three different doses on each $5 \times 5 \mathrm{~mm}$ section. The cooling curve for the heating stage after the $500^{\circ} \mathrm{C}$ irradiation is provided in Figure S3 for reference. The irradiation was conducted under vacuum at $3 \times 10^{-7}$ torr. 


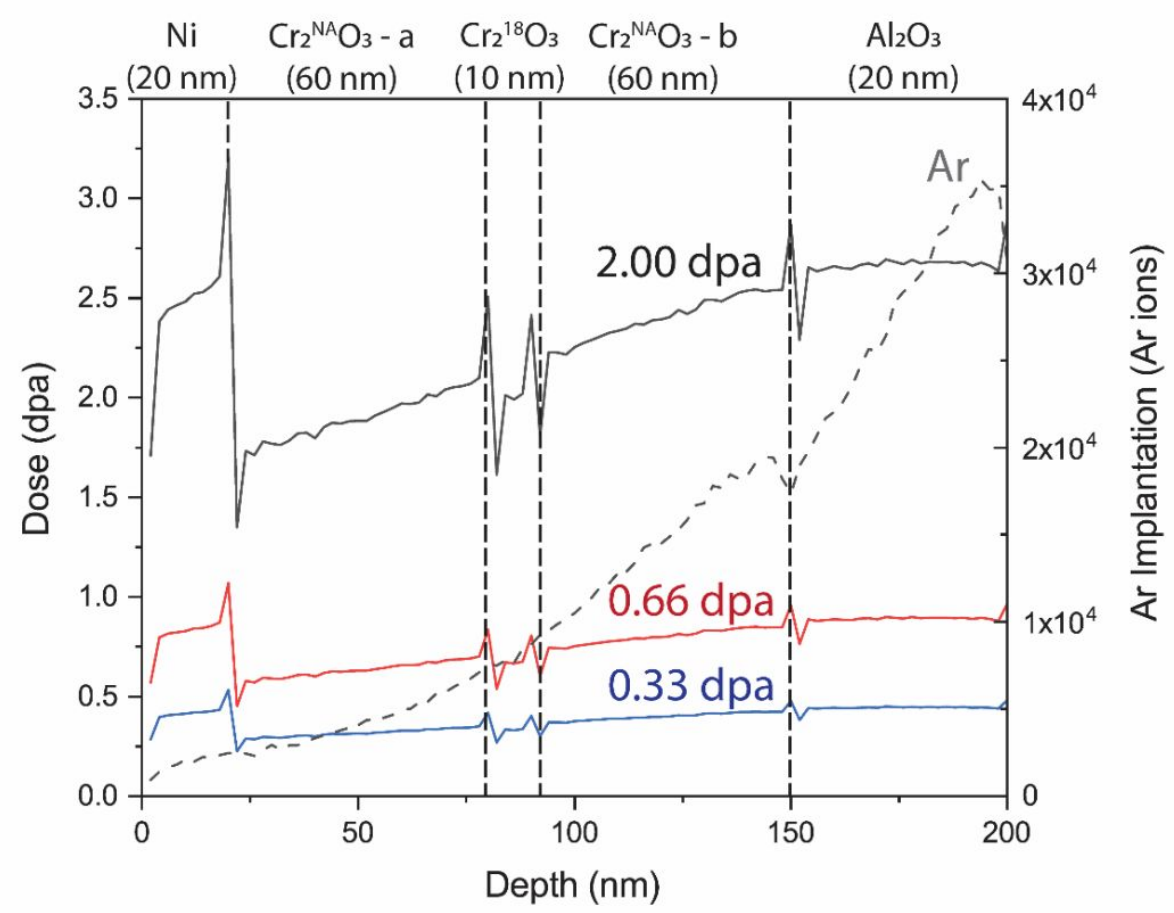

Figure S1. SRIM generated profiles of dose and implantation. Dose profiles target $0.33,0.66$, and 2.00 dpa in $\mathrm{Cr}_{2}{ }^{18} \mathrm{O}_{3}$ layer.

Table S1. Irradiation temperature, dose, times, and fluence for each sample analyzed. Circled numbers correspond to locations in Figure S2. Note that the $300{ }^{\circ} \mathrm{C}$ irradiation was irradiated to a single dose on half the $5 \times 5 \mathrm{~mm}$ piece.

\begin{tabular}{rlrr}
\hline \hline $\begin{array}{c}\text { Temperature } \\
\left({ }^{\circ} \mathrm{C}\right)\end{array}$ & \multicolumn{1}{c}{$\begin{array}{c}\text { Dose } \\
\text { (dpa) }\end{array}$} & $\begin{array}{r}\text { Irradiation } \\
\text { Duration (min) }\end{array}$ & \multicolumn{1}{c}{$\begin{array}{c}\text { Fluence } \\
\left.\text { (ions } / \mathrm{cm}^{2}\right)\end{array}$} \\
\hline 30 & (1) 2.00 & 142 & $3.88 \mathrm{e} 15$ \\
30 & $(2) 0.66$ & 45 & $1.30 \mathrm{E} 15$ \\
30 & (3) 0.33 & 22 & $6.46 \mathrm{E} 14$ \\
300 & 0.66 & 45 & $1.15 \mathrm{E} 15$ \\
500 & (1) 2.00 & 133 & $3.88 \mathrm{e} 15$ \\
500 & (2) 0.66 & 48 & $1.30 \mathrm{E} 15$ \\
500 & (3) 0.33 & 22 & $6.46 \mathrm{E} 14$ \\
\hline \hline
\end{tabular}



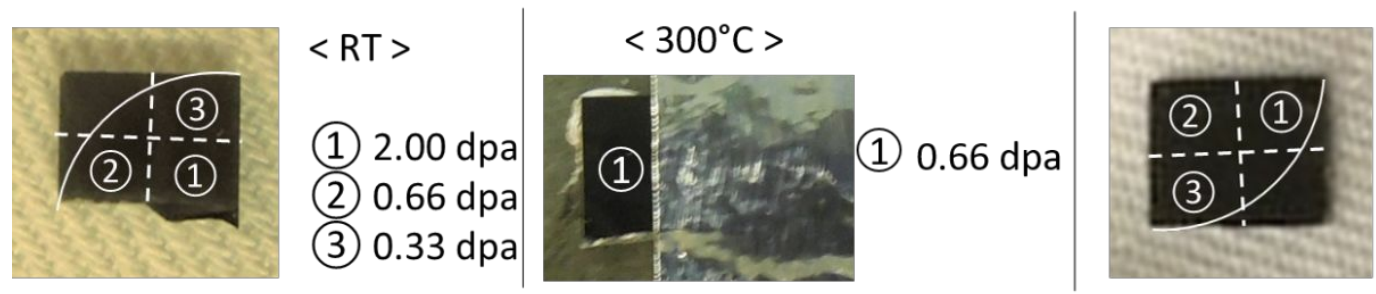

$<500{ }^{\circ} \mathrm{C}>$

(1) $0.66 \mathrm{dpa}$

(1) $2.00 \mathrm{dpa}$

(2) $0.66 \mathrm{dpa}$

(3) $0.33 \mathrm{dpa}$

Figure S2. Irradiation schematic of room temperature and $500^{\circ} \mathrm{C}$ samples. Quarter circle is deposition area. Dotted lines denote masked regions for different irradiation dose.

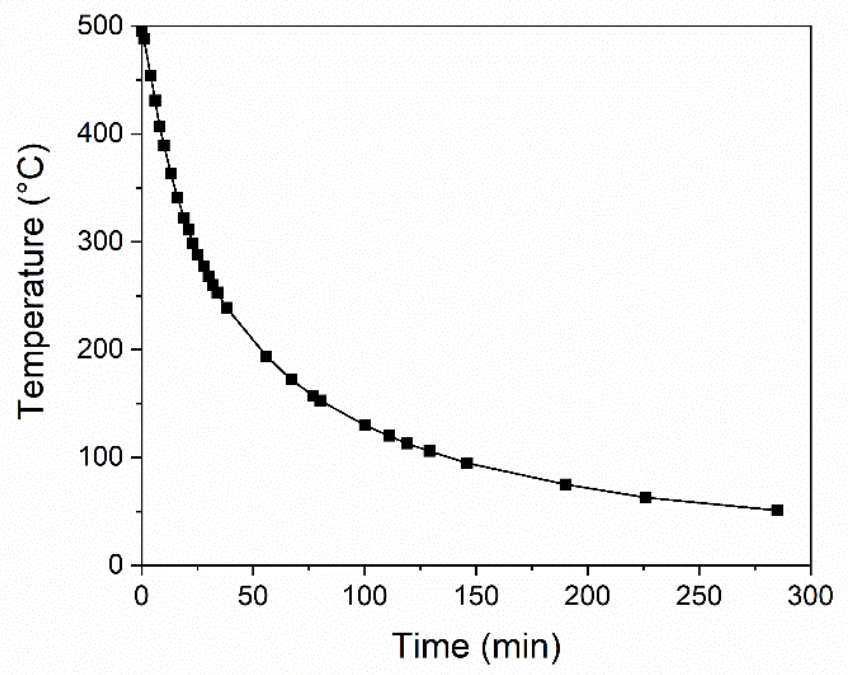

Figure S3. Temperature data from heating stage during cool down after $500^{\circ} \mathrm{C}$ irradiation. 


\section{Atom Probe Tomography}

Figures S4-S8 present additional information from the atom probe tomography (APT) analyses. Figure S4 is a representative mass spectrum of the $\mathrm{Cr}_{2} \mathrm{O}_{3}$ with all major peaks identified. Figure $\mathrm{S} 5$ provides a comparison of APT mass spectra between 15 and 19 Da range containing the $\mathrm{O}^{1+}$ peaks from regions with natural abundance (gray) and highly enriched concentration (red) ${ }^{18} \mathrm{O}$. These isotope-specific $\mathrm{O}^{1+}$

peaks are used to calculate the fraction of ${ }^{18} \mathrm{O}\left(\mathrm{f}_{180}\right)$ as $f_{18 O}=N_{18 O} /\left(N_{18 O}+N_{16 O}\right)$, where $\mathrm{N}_{180}$ and $\mathrm{N}_{160}$ represent the counts of the $16 \mathrm{Da}$ and $18 \mathrm{Da} \mathrm{O}^{1+}$ peaks, respectively. Figure $\mathrm{S} 6$ displays the spatial distribution map (SDM) of a representative $\mathrm{Cr}_{2} \mathrm{O}_{3}$ APT measurement. The SDM reports the periodicity of higher density planes in the depth direction around a crystallographic pole within the APT reconstruction, which in this case correspond to the $\mathrm{O}$ bilayer spacing of $\mathrm{Cr}_{2} \mathrm{O}_{3}$ shown in the accompanying ball-and-stick model (Figure S7). ${ }^{3}$ APT reconstruction parameters (primarily the image compression factor) are manually adjusted to recover the known O bilayer spacing of $\mathrm{Cr}_{2} \mathrm{O}_{3}$ of $0.23 \mathrm{~nm}$. With this correction we routinely achieve a depth scaling reproducibility with $<5-10 \%$ variability, which establishes our approximate scaling accuracy. The spacing is corrected locally after the initial APT reconstruction - see ref ${ }^{4}$. Finally, Figure $S 8$ is a standard 1D concentration profile over an entire, representative APT specimen, with oxygen isotopes separated to show the localization of the ${ }^{18} \mathrm{O}$ enrichment within the sample. 


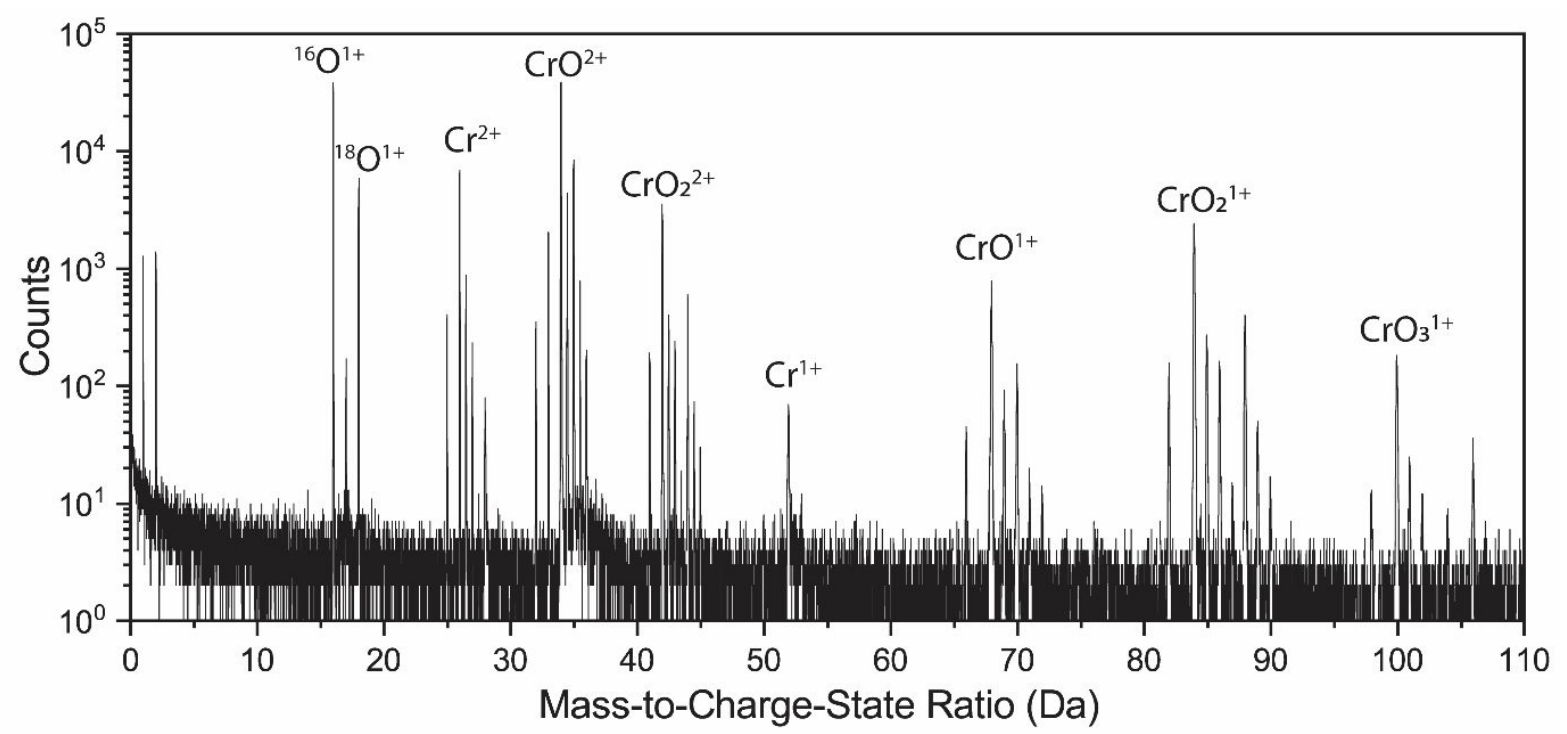

Figure S4. Representative APT mass spectrum for $\mathrm{Cr}_{2} \mathrm{O}_{3}$ including both regions with natural isotopic abundance oxygen and enriched concentrations of ${ }^{18} \mathrm{O}$.

A) $\mathrm{O}^{1+}$ Peaks in ${ }^{18} \mathrm{O}$ and NA layers

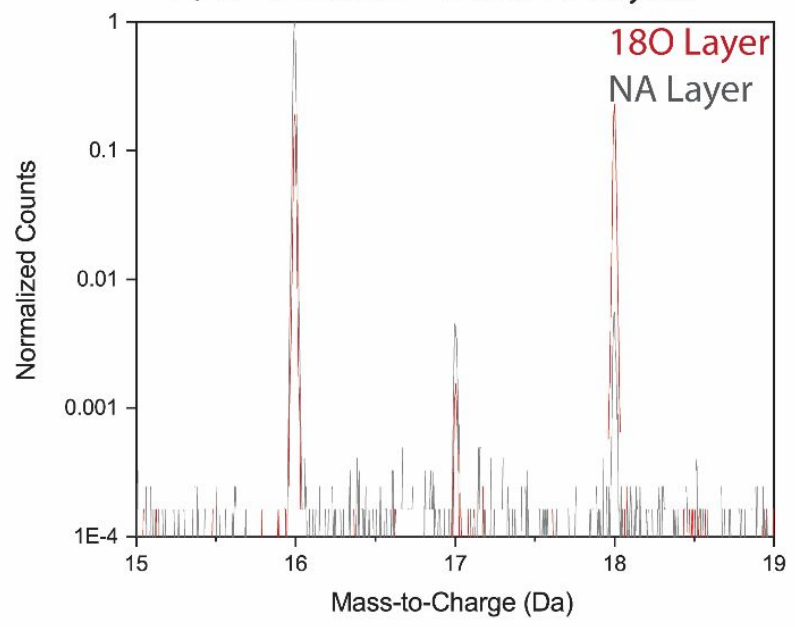

B) $\mathrm{CrO}^{2+}$ Peaks in ${ }^{18} \mathrm{O}$ and NA layers

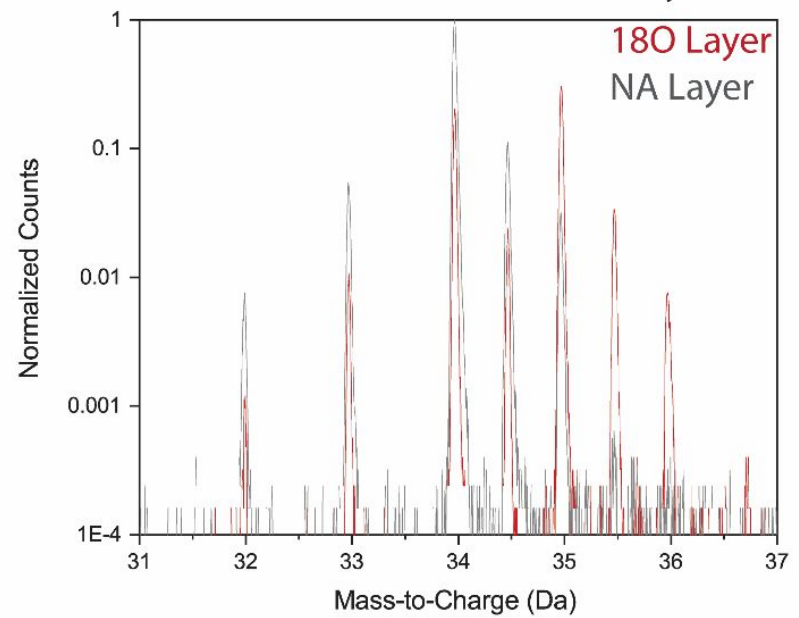

Figure S5. (A) APT mass spectra in the region near $\mathrm{O}^{1+}$ at 16 and $18 \mathrm{Da}$ and (B) APT mass spectra in the region near $\mathrm{CrO}^{2+}$ at $34 \mathrm{Da}$ both with either natural abundance $\mathrm{Cr}_{2} \mathrm{O}_{3}\left(99.76 \%{ }^{16} \mathrm{O}, 0.2 \%{ }^{18} \mathrm{O}\right.$ - gray) and with ${ }^{18} \mathrm{O}$ isotopic enrichment $\left(80-90 \%{ }^{18} \mathrm{O}-\mathrm{red}\right)$. $\mathrm{CrO}^{2+}$ peaks are not used for quantifying $\mathrm{f}_{180}$ due to complications from $\mathrm{O}_{2}{ }^{1+}$ with ${ }^{18} \mathrm{O}$. 


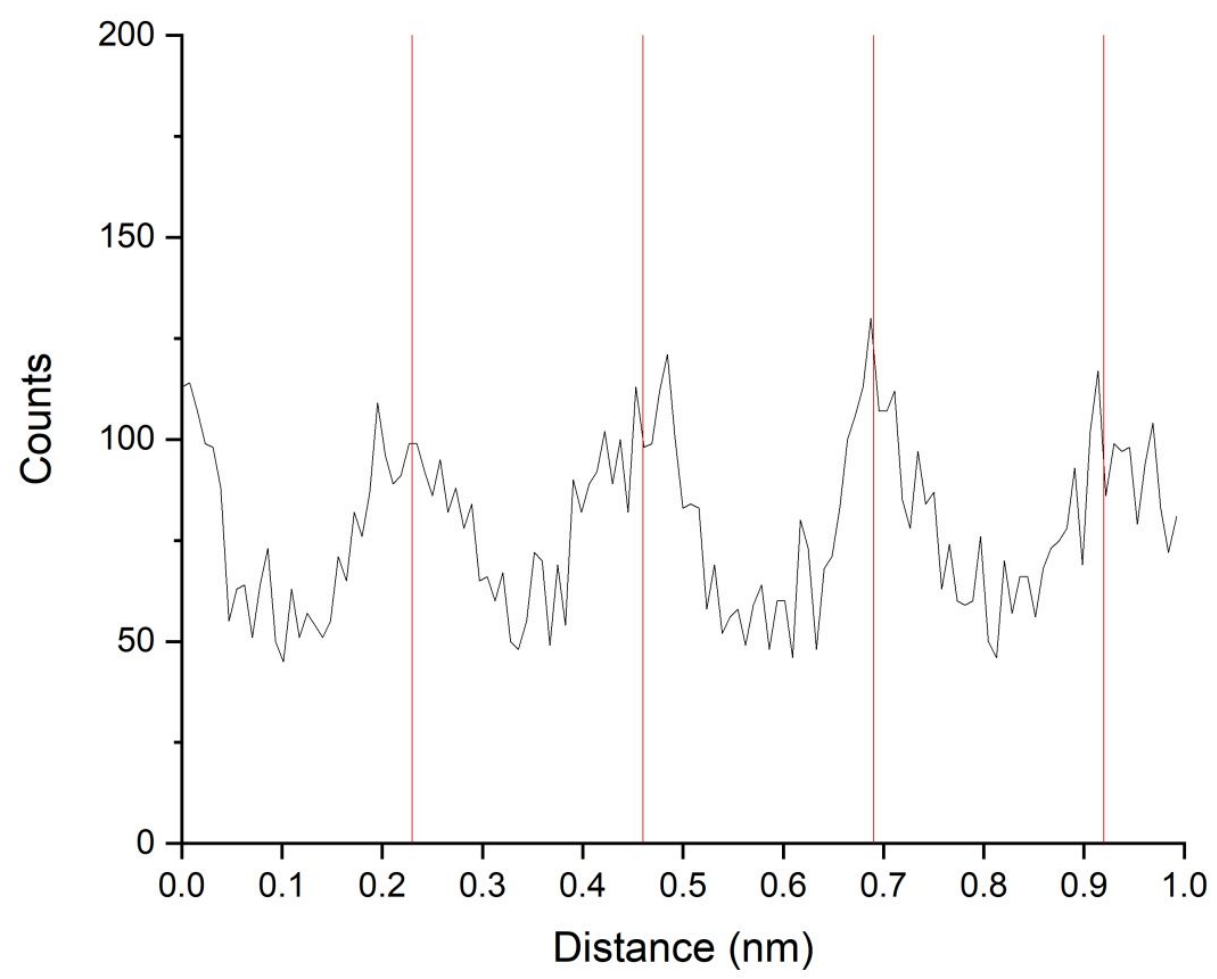

Figure S6. Representative APT spatial distribution map (SDM) in the depth direction of the reconstruction, demonstrating the recovery of the O bilayer spacing of $\mathrm{Cr}_{2} \mathrm{O}_{3}(2.3 \AA)$.

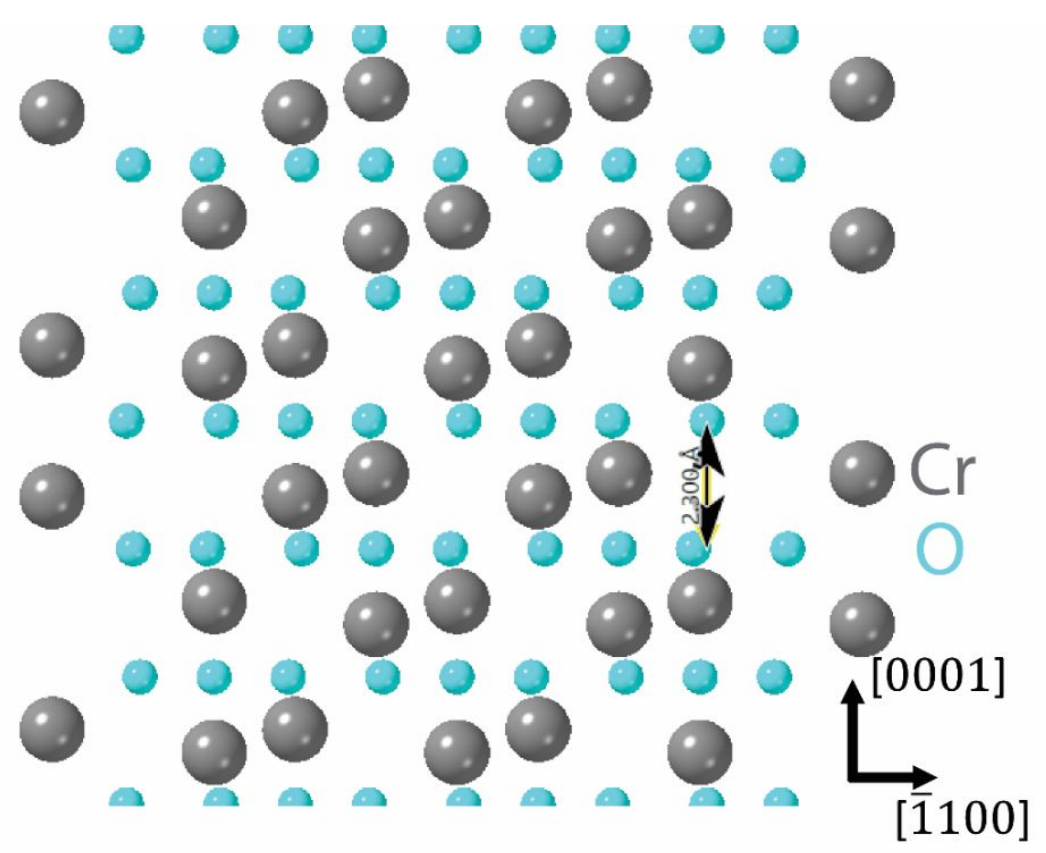

Figure S7. Ball-and-stick model of $\mathrm{Cr}_{2} \mathrm{O}_{3}$ with O bilayer spacing ( $2.3 \AA$ ) identified. ${ }^{5}$ 


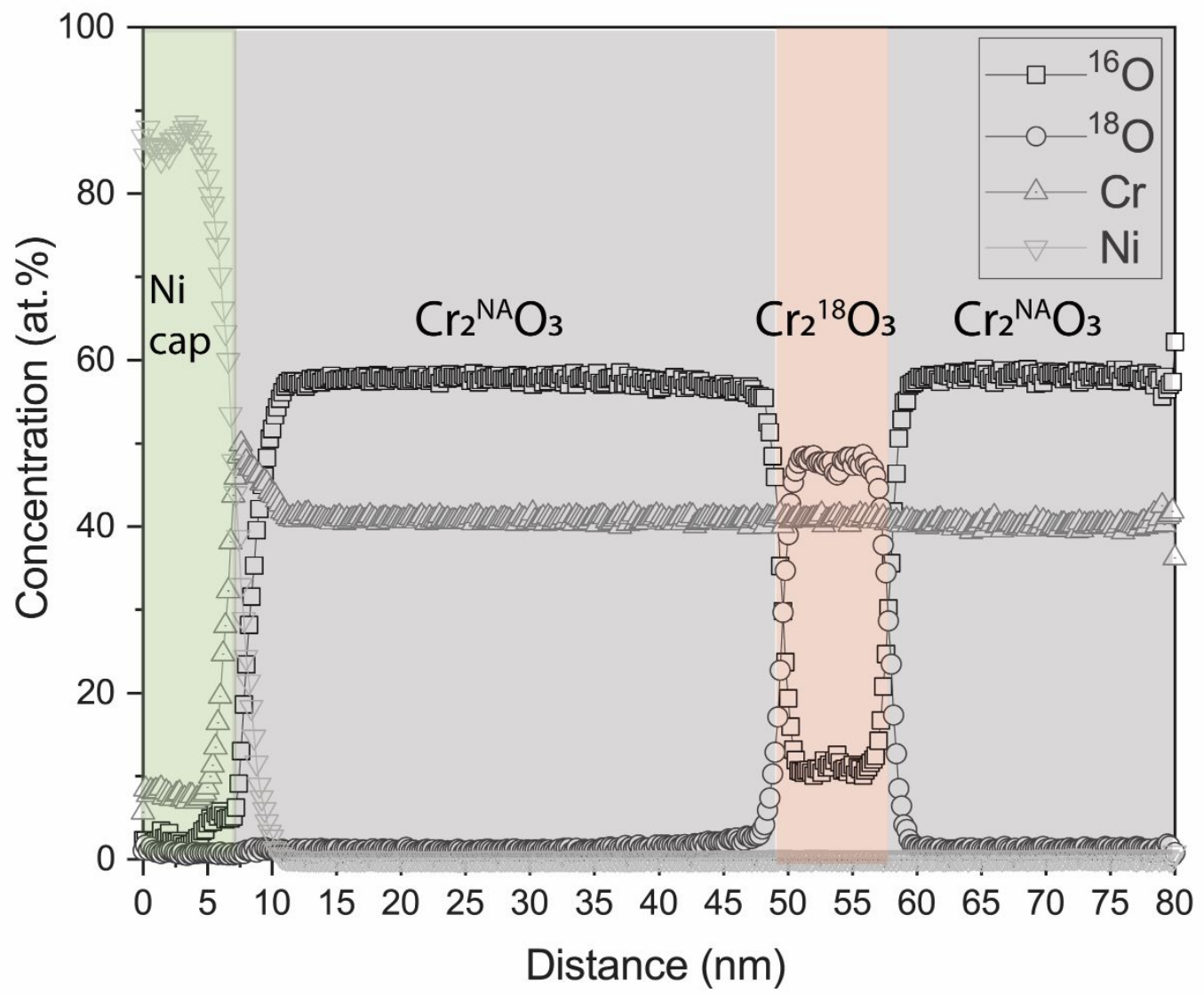

Figure S8. Representative 1D concentration profile of the as-grown stack as measured by APT.

\section{Additional Experimental APT Data and Fitting Curves}

Lastly, additional experimental data is provided here for completeness (Figures S9) as well as the spline fits (Figure S10-S11) used to calculate a best fit and extract a diffusivity value. 

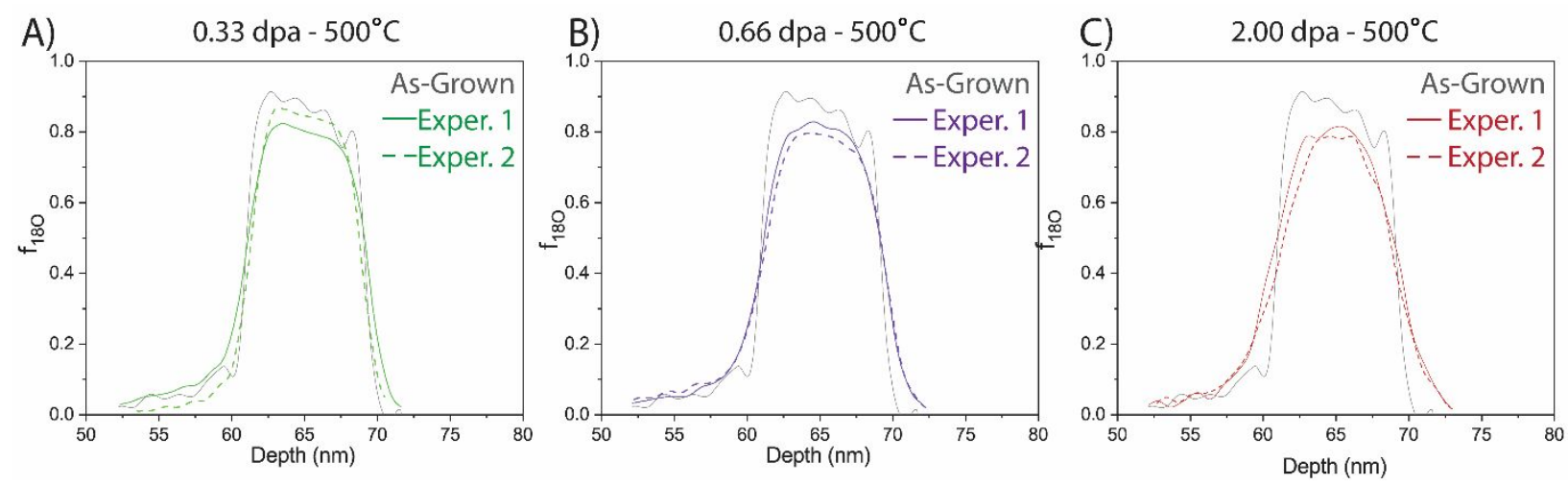

Figure S9. Plots of each APT dataset from dose dependence series with as-grown profile for comparison.

"Exper. 1" and "Exper. 2" refer to separate APT datasets of the same material.
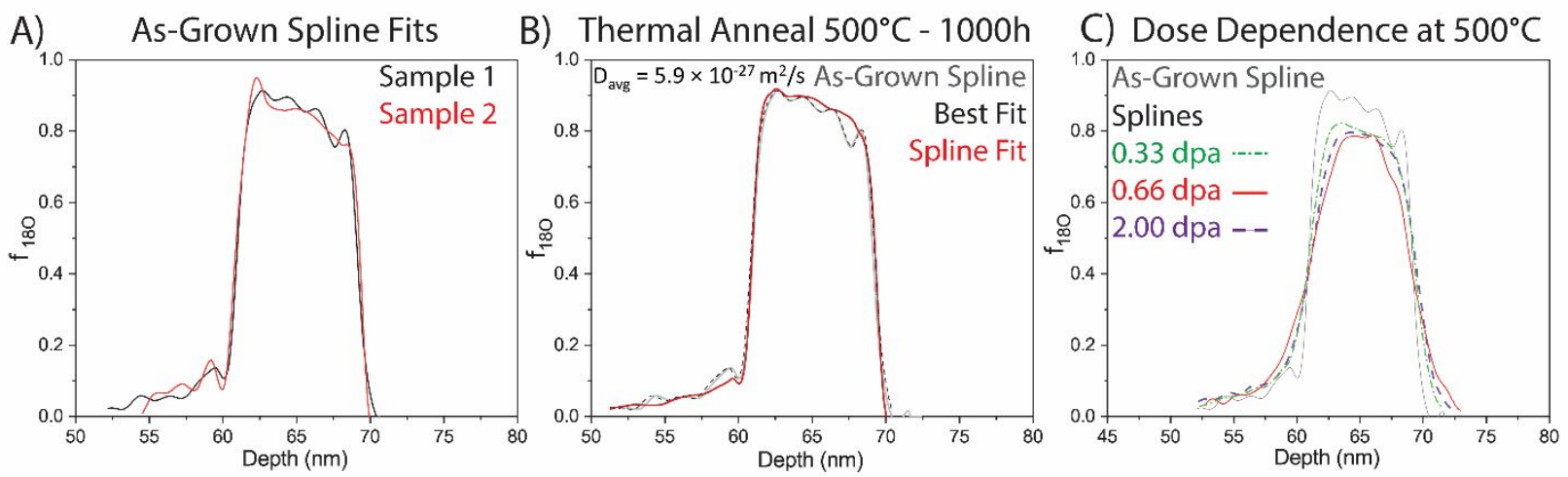

Figure S10. Spline fits of APT data sets used for fitting and diffusivity extraction of Figure 3. 

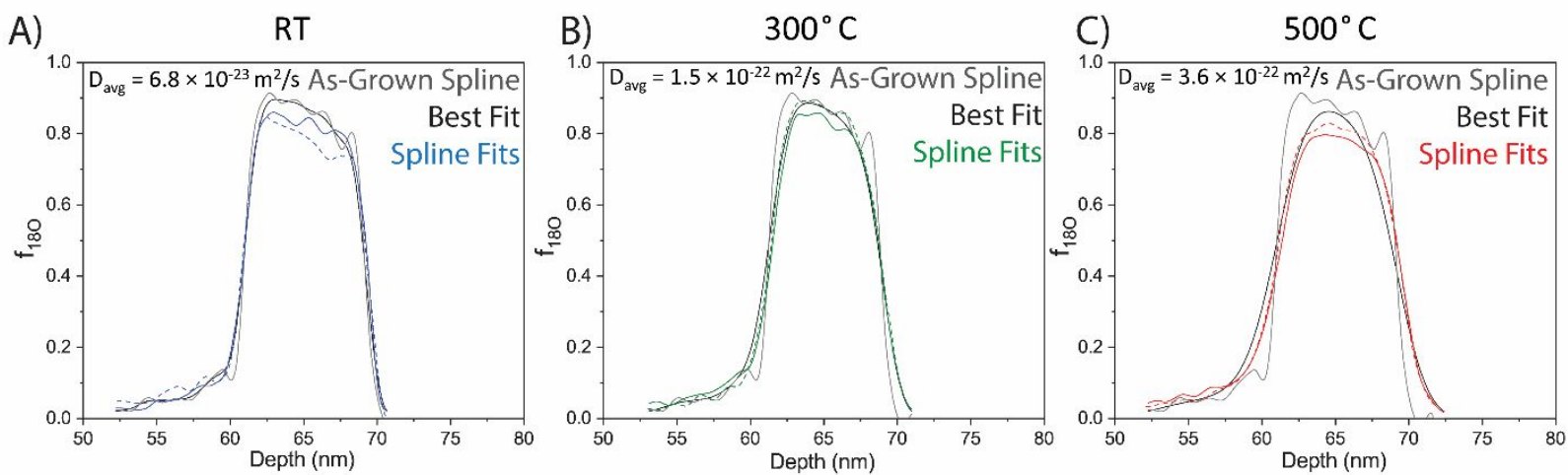

Figure S11. Spline fits of APT data sets used for fitting and diffusivity extraction of Figure 4.

\section{References}

(1) Ziegler, J. F. Stopping Range of Ions in Matter (SRIM). 2013.

(2) E521, A. Standard Practice for Neutron Radiation Damage Simulation by Charged-Particle. Annu. B. ASTM Stand. 2009, 12.02 (Reapproved), 1-21. https://doi.org/10.1520/E0521-96R09E01.

(3) Moody, M. P.; Gault, B.; Stephenson, L. T.; Haley, D.; Ringer, S. P. Qualification of the Tomographic Reconstruction in Atom Probe by Advanced Spatial Distribution Map Techniques. Ultramicroscopy 2009, 109 (7), 815-824. https://doi.org/10.1016/j.ultramic.2009.03.016.

(4) Yano, K. H.; Kohnert, A. A.; Banerjee, A.; Edwards, D. J.; Holby, E. F.; Kaspar, T. C.; Kim, H.; Lach, T. G.; Taylor, S. D.; Wang, Y.; et al. Radiation-Enhanced Anion Transport in Hematite. Chem. Mater. 2021.

(5) CrystalMaker(R) X. Oxford, England. 